line and afterwards the enormous massive ossification, that might be an osteomatous condition. But the true osteomas I have not seen in our material at all.

Firth, $\mathcal{F}$. L. (England). Concerning the point when one should operate or not, these are concerning cases seen at St. Thomas's and Queen Square, I hope I am not stating the obvious, but in a large number of people most of the blood supply to the cervical cord is down the anterior spinal artery which comes from the vertebrals. One can often have a very high cervical or atlanto-axial lesion at that level and yet the case presents a low cervical clinical picture. You block off the arterial supply high in the neck but it presents clinically down at the bottom end of the cervical spine. One has to be aware of a low cervical lesion, with no apparent local clinical picture in the low cervical spine of an arterial block high up, and in many cases you have to do arteriography to investigate the entire set up of the vertebral artery supply of the cervical spine before you can be absolutely certain of the set up in any one particular case.

Harris, P. (Scotland). In relation to the last speaker and what Sir Ludwig has said, I think the blood supply must be extremely important in these patients, and I wonder if Sir Ludwig can tell us something about the mechanism of the cervical injuries in these patients. Did they have hyperextension injuries in particular? Professor Romanes showed here just about a year ago that the blood supply comes mainly from the 5 th cervical radicular artery on one or both sides and very often the lower lesion in the cervical spine will produce a higher neurological lesion. Another practical point is the importance of very careful intubation in any patient with ankylosing spondylitis or rheumatoid arthritis.

Sir Ludwig. With regard to the vascular supply, what our friend has said is absolutely correct. You can have the damage of the vessels much higher and yet get a lower paralysis. But I would say if you have this mechanism you will get probably in the majority of cases (of course there are very few cases so far) incomplete lesions. But, if you look at the A.P. films from these patients carefully, you might have noticed not only the ossification between the cervical vertebrae itself but also between the cervical and the upper costal area and the whole thing was just a mass of ossification, and the question is whether in some of these cases the vascular damage can be lower down. The mechanism which Harris asked me to explain is a very important question. The general views held are that extension fractures either do not produce any spinal cord injuries or minor ones. This is not true and I suggest that, in these cases, the spinal canal itself is very narrowed by the ossification and any sudden change either in flexion or extension leads to injury either of the vascular supply or the spinal cord itself.

\title{
SPINAL CORD COMPRESSION IN A PATIENT WITH ANKYLOSING SPONDYLITIS AND PAGET'S DISEASE
}

\author{
By Richard L. Hewer, M.B., M.R.C.P. \\ United Oxford Hospitals, Neurological Department
}

THE thoracic spinal cord is rarely involved in ankylosing spondylitis and only slightly more commonly in Paget's disease. The present case is reported because of the rarity of such a complication in these two diseases.

Case Report. The patient is a housewife and was born in 1903. At the age of 18 she first developed pain in the mid-thoracic region of the spine. She remained in bed for 
several weeks, but did not call her doctor. Subsequently she has had many episodes of pain in various regions of the back, and later she has had intermittent-pain in the right shoulder; both wrists, and both ankles. At the age of 60 she first developed difficulty with walking, and over a period of months this became progressively worse. At the age of 6I (1964) she was investigated at the Churchill Hospital under the care of Professor W. Ritchie Russell. She was noted to have a marked mid-dorsal kyphosis. There was virtually no movement in the lumbar spine. Chest expansion was one inch. Neurologically the cranial nerves and arms were normal. There was no sensory level on the trunk at this time. There was a spastic paraparesis with some loss of position sense in the toes. X-rays revealed complete fusion of the sacro-iliac joints. X-rays of the lumbar and thoracic spines showed classical changes of ankylosing spondylitis with calcification of the anterior longitudinal ligament and of the interspinous ligament. Some degree of bone rarefaction was noted. Lumbar puncture failed. A cisternal myelogram was done. Initially the myodil would not pass beyond the upper thoracic region, and there appeared to be narrowing of the thoracic spinal canal. Two days later the myodil had reached the lumbar region. No localised block was found. The E.S.R. was $45 \mathrm{~mm}$. and the Differential Agglutination Titre was positive-I/I6.

The patient was seen again six months later. By this time her walking had deteriorated further and she was only able to walk a few yards with two sticks. At this time she was noted to have a clear-cut sensory level on the chest at about the T6 level. On 29 June 1965, an extensive laminectomy was undertaken by Mr. J. Pennybacker. The spinous processes of D2-D8 were removed. The laminae were found to constitute a complete bony wall without any inter-lamina space. The bone itself was rather soft. The vertebral canal appeared to be capacious. The theca was tightly stretched over a gentle thoracic kyphus. The spinal cord itself looked normal. The subarachnoid space was almost non-existent over the area of the kyphus, but was visibly patent above and below this level.

The immediate post-operative course was uneventful. During the subsequent year there has been a very marked improvement in her condition, and at the time of writing she is able to walk half a mile slowly without any difficulty. She herself is extremely pleased with her progress.

At operation a specimen of bone had been taken for histological examination. It was examined by Dr. David Oppenheimer, who reported that the histology was extremely abnormal. There were irregular mosaic lines with abnormal numbers of osteoblasts and osteoclasts. The marrow space was filled with loose vascular connective tissue. These were thought to represent the changes of Paget's disease.

Comment. The mechanism of the paraplegia in this case is still in doubt. It appeared that the thoracic cord was being stretched both by the kyphus and the tight dural sheath. It is noteworthy that paraplegia is uncommonly associated with kyphosis unless there be a traumatic, malignant or inflammatory process causing the spinal deformity. Even when a gross kyphoscoliosis is present, it is comparatively uncommon to get clinical evidence of spinal cord involvement, McKenzie and Dewar (1949).

It will be noted that it was not until the bone biopsy results became available that it was realised that the patient had Paget's disease in addition to ankylosing spondylitis. The spinal cord complications of Paget's disease have been well delineated by Turner (1940), and have been reviewed by Teng et al. (I95I). The latter authors found 37 cases in the literature up to I95 I. Mechanical compression of the spinal cord is the usual cause of the paraplegia. The region between $\mathrm{T}_{2}$ and $\mathrm{T}_{4}$ is most often involved Males are much more frequently involved than females. As in our case, the usinal cord symptoms are frequently the earliest 
manifestations of Paget's disease. At operation the laminae are usually found to be much increased in thickness. Sometimes they are fused without any demarcation between them. The spinal canal is usually diminished in size. A moderate kyphosis is usually present. Twenty out of the 37 cases reviewed by Teng et al. had undergone a laminectomy. Fourteen had made a good improvement.

Turner noted three cases that had a probable vascular origin. No autopsy studies were available on this group. Blackwood (I962) mentiones a case which at post-mortem was found to have bony projections from the dorsal surfaces of the T6 and T8 vertebral bodies. These were apparently producing a compression of the spinal cord.

The author has only been able to find references to three cases of thoracic cord involvement in ankylosing spondylitis. Castaigne et al. (1965) reported on a man aged 57 who had a myelographic hold-up at D5 level. At operation the dura was found to be thickened and tightly stretched. The spinal cord was adherent to the dura. Goldenberg and Logothetis (196I) describe a case of compression of the thoracic spinal cord by an anteriorly situated arachnoid cyst. Lorber, Pearson and Rene (I96I) describe a case with compression of the thoracic spinal cord associated with destructive changes in the adjacent intervertebral discs and vertebrae.

\section{SUMMARY}

A case is presented of upper thoracic spinal cord compression in a patient with ankylosing spondylitis. Bone biopsy showed the changes of Paget's disease, which had been previously unsuspected. The mechanism of the paraplegia in these two conditions is briefly discussed.

\section{REFERENCES}

Blackwood, W. (I963). In: Greenfield's Neuropathology, and ed. London: Edward Arnold. Castaigne, P., Cambier J., Escourolle, R., Masson, M. \& Berger, B. (i965). Bull. Soc. méd. Hôp. Paris, II6, $32 \mathrm{I}$.

Goldenberg, G. J. \& Logothetis, J. (I96I). Lancet, 81, 448.

Lorber, A., Pearson, C. M. \& Rene, R. M. (I96I). Arthr. and Rheum. 4, 5 I8.

McKenzie, K. G. \& Dewar, F. P. (I949). F. Bone ft Surg. 3IB, I62.

Turner, J. W. A. (I940). Brain, 63, 32 I.

Teng, P., Gross, S. W. \& Newman, C. M. (I95 I). F. Neurosurg. 8, 482.

\section{Discussion}

Sir Ludwig. Thank you for this valuable contribution to the problems of traumatic lesions in ankylosing spondylitis. You had the opportunity to rectify the diagnosis in this case, although from the X-rays you showed us there is no doubt a great similarity to true ankylosing spondylitis, The neurological symptoms in Paget's disease are described in a greater number of cases than in ankylosing spondylitis. With regard to the differential diagnosis between genuine ankylosing spondylitis and rheumatoid arthritis I agree that it is sometimes very difficult, unless one takes a very careful history. Although in the well-developed ankylosing spondylitis one can also get changes in the joints of the extremities, these develop more in the proximal joints in later stages, while in rheumatoid arthritis, they start in early youth, as I demonstrated. ne of my cases, where the illness 
started at the age of 13 . That would be very unusual in a genuine ankylosing spondylitis; moreover, rheumatoid arthritis starts in the peripheral joints-in the ankles and fingers. But from the X-ray of that female patient I showed you, one could not distinguish between a genuine ankylosing spondylitis and rheumatoid arthritis.

There are also attempts made to distinguish between ankylosing spondylitis and rheumatoid arthritis from a biochemical point of view. The blood protein changes seem to be different, particularly the gamma protein which is supposed to be increased in the rheumatic arthritis. In our case, gamma was slightly raised but all the other biochemical examinations, phosphatase, phosphorus, and ionised calcium for instance did not allow any real differentiation. There might be some changes in the early stages, and that is a point to which one should draw attention, to do thorough investigations of both the blood, in particular with special reference to calcium and protein.

$M c$ Sweeney, T. (England). I would make one or two points. I think it is true to say that in advanced Paget's disease we do as a terminal phase see neurologically long tract signs. This seldom dictates a surgical approach. I have operated upon one, a localised segmental Paget's in the mid-dorsal region, with scattered Paget's signs in the pelvis and elsewhere, and the surgical approach there was an entirely antero-lateral one to the localised lesion. I think, with all respect, in your case it may well have been a posttraumatic manifestation in an ankylotic spine. With regard to the differential diagnosis of rheumatoid versus ankylosing spondylitis, what Professor Guttmann says, of course, is all too true, and generally speaking you can differentiate between the two by the proximal changes in the ankylosing spondylitis and the distal in rheumatoid arthritis, but of course the more one sees of these two conditions the more one feels that in reality they are six of one and half a dozen of the other. In other words, you get cases where the overlap is very considerable. The only other small addition I would make is that ankylosing spondylitis seldom affects the atlanto-occipital joint, and of course the results of surgery of occipital to upper cervical fusion in our hands are most gratifying.

Araluze, F. (Spain). With regard to differential diagnosis of ankylosing spondylitis and rheumatoid arthritis, it is very important to bear in mind the onset of the disease. There is a very common type of juvenile arthritis which one cannot differentiate at the beginning whether it is going to be ankylosing spondylitis or rheumatoid arthritis later. Another point which I also think is most important is the pattern of joint involvement. In rheumatoid arthritis, particularly in adults, one very seldom sees involvement of the lumbar spine-the pattern of joint involvement is mainly in the cervical and the dorsal spine. In ankylosing spondylitis one sees very seldom erosions in the peripheral joints but these are one of the main features in rheumatoid arthritis. Another thing which Sir Ludwig has pointed out is that the blood gives us a very clear picture in many cases of rheumatoid arthritis.

$P$. Harris (Scotland). I have just two points. Paget's disease usually occurs in an older age-group and I think the alkaline phosphatase is usually raised. Could I ask Dr. Hewer, what the biochemical changes were in his patient.

The second point is one of terminology. We are using different terms, again I think possibly wrongly. We mentioned cervico-cranio occipital subluxation, I think probably we mean atlanto-axial subuxation.

Hewer, R. L. (England). I am afraid the alkaline phosphatase was in fact not doneit was only 4 days ago that I discovered the bone histology on this case. I have shown this to two histologists and there is no doubt at all about the diagnosis of Paget's disease. I have had a further look at her and there is no clinical evidence of Paget's disease-her head size is normal and there is no enlargement of bones. I am sorry, we have not got the alkaline phosphatase but the histology was definite.

$M c$ Sweeny, T. (England). May I say one word on Mr. Harris's question. The alkaline phosphatase in Paget's disease is very variable. It depends whether the patient has been in bed for a time or not. Normally, a Paget's who walks into the clinic, his or her 
blood chemistry will be absolutely normal. If you put the patient in bed for any reason for a fortnight or so then the alkaline phosphatase certainly is raised but not significantly.

Ungar, $G$. (England). With regard to the differential diagnosis between rheumatoid arthritis and ankylosing spondylitis, a common finding, if you look for it, is erosive change in the os calcis. Ankylosing spondylitis sometimes presents pain in the heel, and even without pain you often find changes. Another point is that the costo-vertebral joints are involved early, and even when they do not show radiological change you often find chest expansion reduced to I to $I \frac{1}{2}$ in., in very early cases before there are any other radiological signs, in ankylosing spondylitis.

Sir Ludwig. These are two good points but I doubt whether these ossifications of the calcis and costo-vertebral areas are really very significant differentiation between the two illnesses. The same you could say for instances with the erosions I showed you in practically all our cases on the ischial rami, which were of fluffy type. I think the most important thing of all is the history in these cases: the early start and where.

\section{OBITUARY}

It is with great regret that we have to announce the deaths of the following Members of our Society: Dr. F. W. Bailey, a Urologist in California, U.S.A., and Dr. G. J. Van Hoytema, a well-known Neurosurgeon of Enschede, Holland. Dr. Hoytema published a number of papers on various neurosurgical subjects, amongst them treatment of spasticity, intervertebral disc and diagnosis and treatment of spinal tumour with special reference to rehabilitation. 